Klinik Araştırma/Clinical Research

\title{
Spinal ve epidural anestezinin QT dispersiyonuna etkisi
}

\section{QT dispersion effect of spinal and epidural anesthesia.}

\author{
Fatih Özkan*a, Mustafa Çakır ${ }^{a}$, Orhan Önalan ${ }^{b}, Z_{1 y a} K^{a y a}{ }^{a}$, Ünal Erkorkmaz ${ }^{c}$ \\ a Gaziosmanpaşa Üniversitesi, Tip Fakültesi, Anesteziyoloji ve Reanimasyon Anabilim Dall, Tokat \\ ${ }^{b}$ Gaziosmanpaşa Üniversitesi, Tip Fakültesi, Kardiyoloji Anabilim Dall, Tokat \\ ${ }^{c}$ Gaziosmanpaşa Üniversitesi, Tip Fakültesi, Biyoistatistik ve Tip Bilişsimi Anabilim Dall, Tokat
}

\begin{tabular}{|c|c|}
\hline МАКА & IILERİ \\
\hline \multicolumn{2}{|c|}{ Makale Geçmişi: } \\
\hline Geliş & $26 / 02 / 2010$ \\
\hline Kabul & $01 / 04$ / 2010 \\
\hline \multicolumn{2}{|c|}{$\begin{array}{l}\text { * Yazışma Adresi: } \\
\text { Fatih Özkan } \\
\text { Ondokuz Mayıs Üniversitesi, Tıp Fakültesi, } \\
\text { Anesteziyoloji ve Reanimasyon AD., } \\
\text { Kurupelit, Samsun } \\
\text { e-posta:dr.fat.oz@hotmail.com }\end{array}$} \\
\hline
\end{tabular}

\section{Anahtar Kelimeler: \\ Spinal Anestezi \\ Epidural Anestezi \\ Elektrokardiografi \\ Kardiyak Aritmi \\ Lokal Anestezikler \\ Bupivakain}

\section{Key Words : \\ Spinal Anesthesia \\ Epidural Anesthesia \\ Electrocardiography \\ Cardiac Arrytmias \\ Local Anesthetics \\ Bupivacaine}

\section{ÖZET}

Kardiyak veya nonkardiyak hastaların incelendiği pek çok çalışmada QT aralığ1 ve QT dispersiyonunun kardiyak olarak prognostik önemi gösterilmiştir. Bu çalışmada; iki farklı santral blok şekli olan spinal ve epidural anestezi yöntemlerinin QT intervali üzerine etkilerinin karşılaştırılması planlandı.Çalışmaya elektif şartlarda rejyonel anestezi planlanan, ASA I-II grubu 60 erişkin hasta kabul edildi. Hastalara anestezi öncesi Multipurpose Digital ECG holter takıldı. Hastalar epidural (Grup E, n=30) ve spinal anestezi (Grup S, $\mathrm{n}=30$ ) olmak üzere randomize iki gruba ayrıldı. Epidural anestezi $100 \mathrm{mg} \% 0,5$ izobarik bupivakain (20ml) ile, spinal anestezi ise $15 \mathrm{mg} \% 0,5$ izobarik bupivakain (3 ml) ile L3 - L4 veya L4 - L5 mesafesinden uyguland. Duyusal bloğu T10 dermatom seviyesine ulaşan hastalarda cerrahi operasyona izin verildi. Preoperatif ve intraoperatif hemodinamik bulgular ve QT değerleri ve QTa (QT apeks) ölçümleri kaydedildi.Preoperatif kalp hızı ve ortalama arter basıncı değerlerinin işlem süresince hemodinamik stabiliteyi etkilemeyecek şekilde düştüğü ve bu düşmenin her iki grupta benzer olduğu görüldü. Epidural ve spinal anestezi uygulanan hastalarda grup içi değerlendirmede QTa değerlerinde rejyonel anestezi sonrasında anlamlı bir artış saptandı $(\mathrm{p}<0,05)$. QTa uzaması açısından her iki grup birbiri ile karşılaştırıldığında ise aralarında fark olmadığı görüldü $(\mathrm{p}>0,05)$. QT dispersiyonu, miyokardın repolarizasyonda homojenliğinin bozulmasının ve aritmiye yatkınlığının noninvaziv bir göstergesidir. Çalışmamızda QT intervali açısından değerlendirildiğinde her iki yöntemin kardiyak etkilerinin benzer olduğu bir yöntemin diğerine üstün olmadığı kanısına varıldı

J. Exp. Clin. Med., 2009; 26:157-162

\begin{abstract}
Many studies showed that QT interval and QT dispersion are important as a prognostic factor in cardiac and non-cardiac patients. In this study, we aimed to compare effects of the spinal and epidural anaesthesia which are two different model of the central regional anaesthesia on QT interval. Study group was consisted of 60 adult patients who are ASA I-II and planned the regional anesthesia for elective operations. Before the anaesthesia, Multipurpose Digital ECG holter was placed to the patients. Patients randomly divided into two groups as an epidural anaesthesia $(n=30)$ and spinal anaesthesia $(n=30) .100 \mathrm{mg} 0,5 \%$ isobaric bupivacaine $(20 \mathrm{ml})$ was given for epidural anaesthesia and $15 \mathrm{mg} 0,5 \%$ isobaric bupivacaine (3 ml) was given spinal anaesthesia at the L3 - L4 or L4 - L5 intervertebral spaces. The surgical operation was allowed in patients when the sensory block reached the T10 dermatome level. The preoperative and postoperative hemodynamic parameters, QT intervals and QTa (QT apex) measurements were evaluated. The preoperative heart rate and mean arterial pressure values had decreased during the process without any effect on the hemodynamic stability and this rise was similar in both groups. There was significant increase in the QTa values after regional anaesthesia within the epidural and spinal anaesthesia groups $(\mathrm{p}<0.05)$. When the groups were compared in terms of prolonged $\mathrm{QTa}$, significant difference was not founded ( $\mathrm{p}>0.05)$. QT dispersion is an important noninvasive indicator for deterioration of myocardial homogenity in repolarization and predisposition to the arrhythmia. In our study, the cardiac effects of both methods in terms of QT interval was similar and there was no obvious superiority to another.

J. Exp. Clin. Med., 2009; 26:157-162
\end{abstract}

(C) 2009 OMÜ Tüm Hakları Saklıdır. 


\section{Giriş ve Amaç}

Spinal ve epidural anestezi özellikle alt batın ve alt ekstremite operasyonlarında, yaygın olarak kullanılan bölgesel anestezi teknikleridir (Kayhan, 2004; Erdine, 2005). Rejyonel anestezinin şuurun açık olması, spontan solunumun korunması, pulmoner fonksiyonların korunması, mide içeriğinin aspirasyon riskinin azalması, tromboemboli riskinin azalması, kanama ve transfüzyon gereksiniminin azalması, üst abdominal ve torasik girişimlerden sonra ağrıya bağlı olarak gelişen solunum depresyonunun azalması, operasyon sonrası analjezi sağlanması, ayrıca gastrointestinal fonksiyonun erken dönmesi ve cerrahiye nöroendokrin stres yanıtı azaltarak postoperatif morbidite ve mortalitenin azaltılması gibi olumlu etkileri vardır (Erdine, 2005). Olumlu etkilerinin yanı sıra bloğun seviyesiyle ilişkili olarak direkt kardiyak ve sempatik denervasyona bağlı vazodilatasyon, sağ kalp basıncının düşmesi ve refleks bradikardi (Bain-bridge refleksi) gibi indirekt kardiyak yan etkiler görülebilir (Collins, 1993).

Lokal anestezikler sinir hücre membranlarındaki iyon kanallarını bloke ettikleri gibi diğer uyarılabilir dokulardaki kanalları da bloke ettiklerinden potansiyel kardiyovasküler toksisiteleri vardır (Chester ve Bleckner, 2005). Doğrudan etkileriyle kardiyak debide azalma, hipotansiyon, kardiyak arreste yol açabilecek ventriküler taşikardi ve kalp bloğu göstergesi olan EKG (Elektrokardiyografide) değişikliklerini de içeren kardiyotoksisite görülürken, dolaylı etkileriyle sempatik kardiyak innervasyonun blokajı ile ilgili bulgular görülebilir (Kayhan, 2004). Amid yapılı uzun etkili bir lokal anestezik ajan olan bupivakain kardiyak depresan etkisi olmasına rağmen yıllardır kullanılan standart bir lokal anesteziktir (Kayaalp, 1990; Kayhan, 2004). Bupivakain ile EKG'de QRS kompleksinde genişleme, P-R'de uzama, A-V blok, QT uzaması, ventriküler aritmi görülebilir, hipotansiyon ve bradikardi gelişebilir (Bardsley ve ark., 1994; Kayhan, 2004; Chester ve Bleckner, 2005).

EKG'de ventrikül depolarizasyonu ve repolarizasyonu için gereken zamanı ifade eden QT mesafesi QRS kompleksinin başlangıcından $\mathrm{T}$ dalgasının sonuna kadar olan zaman aralığıdır. QT intervalinin derivasyonlar arasındaki farkı, bölgesel repolarizasyon farklılığını gösterir. QT dispersiyonu (QTd) ise 12 derivasyonlu EKG'de ölçülen en uzun QT mesafesi ile en kısa QT mesafesi arasındaki farktır. QTd artışı ventriküler aritmilerin ve ani kardiyak ölümlerin önemli bir göstergesidir (Akçay ve ark., 2004). Kalp hızının artması veya azalması QT mesafesinde değişikliğine neden olduğu için QT süresinin beklenen değerlerde olduğunu veya anormal olarak uzadığını söylemek için kalp hızı hesaplanmalıdır. QTc (düzeltilmiş-corrected QT) ise kalp hızı dikkate alınarak ve bazı formüllere göre düzeltilmiş QT değeridir (Akçay ve ark., 2004). QT dispersiyonu esas olarak, repolarizasyonun minimal süresinin azalmasından daha çok maksimum sürenin artmasından kaynaklanır. Son bilgiler, QT interval süresinin bütününün artmasından daha çok, QT apeks (QTa) intervalindeki uzamanın, artmış prekordial dispersiyonu yansıttığını göstermektedir ( Iretedt ve ark., 1997; Erdine, 2005). QTac (düzeltilmiş-corrected QTa), kalp hızına göre düzeltilmiş QTa değerini, QTacd (düzeltilmiş QT apeks dispersiyonu) ise kalp hızına göre düzeltilmiş QTa dispersiyonunu ifade etmektedir

Bu çalışmada elektif cerrahi için uygulanan rejyonel anestezi (spinal anestezi veya epidural anestezi) yönteminin QTa üzerine etkilerinin karşılaştırılması amaçlandı. Literatürde her iki rejyonel anestezi yönteminin QTa üzerine etkilerini karşılaştıran çalışmaya rastlanmamıştır.

\section{Gereç ve Yöntem}

Bu çalışma Gaziosmanpaşa Üniversitesi Tıp Fakültesi Etik Kurulu onayı ve çalışmaya katılan hastalardan bilgilendirilmiş hasta onamı alındıktan sonra yapıldı. Elektif ortopedik alt ekstremite cerrahisi uygulanacak ve rejyonel anestezi altında ameliyat olmayı kabul eden ve kontrendikasyonu olmayan 22-68 yaş arası ASA I-II grubu 60 hasta çalışmaya dahil edildi. Hastalar rastgele olarak epidural anestezi grubu (Grup E, n=30), spinal anestezi grubu (Grup $\mathrm{S}, \mathrm{n}=30$ ) olacak şekilde iki gruba ayrıldı. Rejyonel anestezinin kontrendike olması, QT uzamasına sebep olan kalp hastalıkları, QT uzamasına sebep olan ilaç kullanımı varlığı, ritm bozuklukları ve elektrolit bozukluğu olan hastalar çalışma dişı birakıldı.

Ameliyathaneye alındıktan sonra hastalara Spider View the Multipurpose Digital ECG Holter tak1ldı ve SIEMENS SC 7000 ile EKG, puls oksimetre ve noninvazif kan basıncı monitörizasyonu yapıldı. El üstü veya antekubital fossa venlerinden 18 gauge kanül ile damar yolu açılan hastalara her iki gruba anestezi öncesi $10 \mathrm{ml} / \mathrm{kg} \% 0,9^{\prime} \mathrm{luk}$ izotonik $\mathrm{NaCl}$ ile 30 dakika volüm replasmanı yapıldı. Preoperatif dönemden başlayarak 20.dakikaya kadar 3 dakikada bir, daha sonra 5 dakikada bir aralıklarla 45.dakikaya kadar ölçümler kaydedildi. Sistolik arter basıncı (SAB) 80 mmHg veya ortalama arteryel basınç (OAB) 60 mmHg'nın altına düşmesi hipotansiyon olarak olarak kabul edildi ve öncelikle iv S1v1 replasmanı yapılarak tedavi edildi. Hipotansiyonun düzelmemesi halinde 5-10 mg efedrin iv bolus olarak uyguland1. Kalp atım hızı (KAH) 50 vuru/dk altına düşmesi bradikardi olarak kabul edildi ve $0,5 \mathrm{mg}$ atropin iv bolus uyguland. El üstü veya antekubital fossa venlerinden 18 gauge kanül ile damar yolu açılan hastalara her iki gruba anestezi öncesi $10 \mathrm{ml} / \mathrm{kg} \% 0,9$ 'luk izotonik $\mathrm{NaCl}$ ile 30 dakika volüm replasmanı yapıldı. Peroperatif dönemde maske ile $2 \mathrm{~L} /$ dk oksijen verildi.

Grup E'de epidural anestezi uygulanacak hastalar oturur pozisyonda iken ponksiyon bölgesi \%10'luk povidon iyot antiseptik çözeltisi ile dezenfekte edildi. Steril örtümden sonra uygun vertebral aralıktan (L3-L4 veya L4L5) $2 \mathrm{ml} \% 2$ 'lik lidokain ile cilt ve cilt altına lokal anestezi uygulandı.18 gauge Touhy iğnesi ile orta hat yaklaşımı ve 
direnç kaybı tekniği kullanılarak epidural aralık belirlendi. Epidural aralık doğrulandıktan sonra epidural kateter sefalik yönde $4 \mathrm{~cm}$ ilerletildi. Aspirasyonda kan ya da BOS gelmediği görüldükten sonra test dozu olarak $3 \mathrm{ml}(15 \mathrm{mg})$ izobarik bupivakain hidroklorür $15 \mathrm{sn}$ içinde verildi. Üç dakika beklendikten ve kateterin intratekal veya intravenöz yerleşimli olmadığına karar verildikten sonra $20 \mathrm{ml}$ (100 mg) \%0,5 izobarik bupivakain hidroklorür ortalama $2 \mathrm{dk}$ içerisinde epidural kateterden uygulandı. Bupivakain hidroklorür enjeksiyonu esnasında aralıklı olarak aspirasyon uygulanılarak kateterin yerinde olduğu kontrol edildi. Enjeksiyonun tamamlanmasıyla birlikte Holter aktive edilerek zaman 0'inc1 dakika olarak belirlendi ve elde edilen bulgular kaydedildi.

Grup S'de ise spinal anestezi uygulanacak hastalar Grup E'ye benzer olarak uygun arıtım ve örtümden sonra seçilen intervertebral aralıktan (L3-L4 veya L4-L5) 25 gauge keskin uçlu spinal iğneyle subaraknoid mesafeye girildi. Serbest BOS gelişi gözlendikten sonra hastalara $3 \mathrm{ml}(15$ $\mathrm{mg}) \% 5$ 'lik izobarik bupivakain hidroklorür verildi. Enjeksiyonun tamamlanmasıyla birlikte Holter aktive edilerek zaman 0'1ncı dakika olarak belirlendi ve elde edilen bulgular kaydedildi.

Her iki grupta da enjeksiyonu takiben hastalar supin pozisyona getirilerek başları 30 derece yükseltildi. Olgularda duyusal blok düzeyi iğne batırma yöntemi ile (pinprick testi) değerlendirildi. Ayrıca motor blok modifiye Bromage $\operatorname{Skalas} 1(0=$ motor blok yok, $1=$ kalçadan fleksiyon yok, $2=$ dizden fleksiyon yok, $3=$ ayak bileği veya ayak hareketi yok) ile değerlendirildi. Duyusal blok T10 dermatom seviyesine ulaştı̆̆ında cerrahi operasyona izin verildi. Duyusal blok düzeyi daha düşük seviyede kalan hastalar çalışma dış1 bırakıld1. Hastalarda spinal ve epidural enjeksiyon sonras1 2 , $5,10,15,20$. dak'da duysal ve motor blok seviyesi değerlendirildi.

QT ölçümü rejyonel anestezi öncesi ve blok sonrası $0,3,6,9,12,15,30,45,60$. dk'larda olmak üzere 10 periyotta yapıldı. Holter kayıtlarından elde edilen QT aralığı hesaplamalarında Synescope software 3.10 holter programı kullanıldı.

\section{İstatistiksel Analiz:}

Çalışmada kullanılan kategorik değişkenlerin gruplar arası karşılaştırmalarında Ki-Kare testi kullanıldı. Kategorik değişkenler sayı ve yüzde ile ifade edildi. Sürekli değişkenler Kolmogorov-Smirnov normallik testine göre normal dağılım gösterdiğinden dolayı, gruplar arasındaki karşılaştırmalarda İki Ortalama Arasındaki Farkın Önemlilik testi kullanıldı. Sürekli değişkenler Aritmetik Ortalama (Ort.) ve Standart Sapma (SS) ile ifade edildi. $\mathrm{p}<0.05$ değeri istatistiksel olarak anlamlı kabul edildi. Hesaplamalar istatistik paket programı ile yapıldı (SPSS inc, Chicago, IL).

\section{Bulgular}

Cinsiyet, ASA, yaş, boy, kilo ve vücut kitle indeksi gibi demografik veriler açısından iki grup arasında istatistiksel anlamlı fark bulunmadı $(\mathrm{p}>0,05)$ (Tablo 1).

İki grup arasında periyodik ölçümler arasında $\mathrm{KAH}$ yönünden istatistiksel olarak önemli bir fark bulunmadı $(\mathrm{p}>0,05)$. Grup içi değerlendirmelerde ölçülen KAH degerleri arasında ise her iki grupta preoperatif KAH'na göre diğer KAH değerlerinin düştüğü görüldü $(p<0,001)$. Gruplar arası değerlendirmede epidural anestezi uygulanan grupta preoperatif değere göre KAH'daki düşüş spinal anestezi uygulanan gruba göre daha az olmasına karşın bu fark istatistiksel olarak anlamlı değildi ( $\mathrm{p}>0,05)($ Tablo 2).

Tablo 1. Demografik özelliklerin dağılımı

\begin{tabular}{|l|l|l|}
\hline Özellikler & $\begin{array}{l}\text { Epidural } \\
(\mathrm{n}=30)\end{array}$ & $\begin{array}{l}\text { Spinal } \\
(\mathrm{n}=30)\end{array}$ \\
\hline Cins (E/K) & $20 / 10$ & $9 / 11$ \\
\hline ASA (I/II) & $9 / 21$ & $5 / 25$ \\
\hline Yaş (yl) (Ort \pm SS) & $53,79 \pm 13,12$ & $51,97 \pm 15,41$ \\
\hline Kilo (kg) (Ort \pm SS) & $74,00 \pm 13,24$ & $75,63 \pm 12,98$ \\
\hline Boy (cm) (Ort \pm SS) & $168,00 \pm 7,69$ & $167,17 \pm 8,50$ \\
\hline Vücut Kitle İndeksi (Ort \pm SS) & $26,41 \pm 5,78$ & $27,20 \pm 5,24$ \\
\hline
\end{tabular}

İki grup arasında $\mathrm{OAB}$ yönünden peryodik ölçümler arasında başlangıç ölçümü hariç aynı periyotlarda $\mathrm{OAB}$ yönünden istatistiksel olarak anlamlı bir fark bulunmadı ( $>00,05)$. Grup içi değerlendirmelerde ise her iki grupta preoperatif $\mathrm{OAB}$ 'nna göre diğer $\mathrm{OAB}$ değerlerinin düştügü görüldü $(p<0,001)$. Gruplar aras1 değerlendirmede ise epidural anestezi uygulanan grupta preoperatif değere göre OAB'daki düşme spinal anestezi uygulanan gruba göre daha az olmasına karşın bu fark istatistiksel olarak anlamlı değildi $(\mathrm{p}>0,05)$ (Tablo 3$)$.

Tablo 2. KAH değerlerinin gruplara göre karşılaştırılması

\begin{tabular}{|c|c|c|c|c|}
\hline & EPİDURAL & SPINAL & \multirow[t]{2}{*}{$T$} & \multirow[t]{2}{*}{$\mathbf{P}$} \\
\hline & Ort \pm ss & Ort \pm ss & & \\
\hline КАН preop & $81,40 \pm 11,76$ & $83,70 \pm 14,09$ & 0,686 & 0,495 \\
\hline КАН 0 & $81,60 \pm 12,22$ & $83,80 \pm 13,63$ & 0,658 & $\mathbf{0 , 5 1 3}$ \\
\hline КАН 3 & $80,57 \pm 12,41$ & $83,23 \pm 14,13$ & $\mathbf{0 , 7 7 7}$ & 0,440 \\
\hline КАН 6 & $80,94 \pm 13,50$ & $83,53 \pm 14,50$ & 0,719 & 0,475 \\
\hline КАН 9 & $80,23 \pm 12,64$ & $82,20 \pm 15,04$ & 0,548 & $\mathbf{0 , 5 8 6}$ \\
\hline КАН 12 & $79,90 \pm 13,52$ & $80,17 \pm 13,96$ & 0,075 & 0,940 \\
\hline КАН 15 & $78,97 \pm 11,73$ & $78,00 \pm 13,02$ & $-0,302$ & 0,764 \\
\hline КАН 20 & $77,27 \pm 11,30$ & $74,93 \pm 11,96$ & $-0,776$ & 0,441 \\
\hline КАН 25 & $76,90 \pm 12,81$ & $73,20 \pm 11,75$ & $-1,166$ & $\mathbf{0 , 2 4 8}$ \\
\hline КАН 30 & $75,57 \pm 11,32$ & $72,37 \pm 10,85$ & $-1,118$ & 0,268 \\
\hline КАН 35 & $74,83 \pm 11,10$ & $73,10 \pm 11,45$ & $-0,596$ & $\mathbf{0 , 5 5 4}$ \\
\hline КАН 40 & $73,43 \pm 10,75$ & $71,67 \pm 11,39$ & $-0,618$ & $\mathbf{0 , 5 3 9}$ \\
\hline \multirow[t]{4}{*}{ КАН 45} & $72,87 \pm 10,68$ & $70,80 \pm 11,61$ & $-0,717$ & 0,476 \\
\hline & $F=1544,88$ & $F=1356.56$ & & \\
\hline & $\mathbf{P}<0,001$ & $\mathbf{P}<0,001$ & & \\
\hline & \multicolumn{2}{|c|}{$F=0,010, \quad P=0,921$} & & \\
\hline
\end{tabular}


İki grup arasında peryiodik ölçümlerde QTa yönünden istatistiksel olarak anlamlı bir fark bulunmadı $(p>0,05)$. Grup içi değerlendirmede ise her iki grupta preoperatif QTa değerlerine göre diğer QTa değerlerinin düştüğü görüldü $(p<0,001)$. Gruplar arası değerlendirmede, epidural anestezi grubundaki QTa değişimi ile spinal anestezi grubundaki QTa değişimi arasında istatistiksel olarak anlamlı fark bulunmadı $(\mathrm{p}>0,05)$ (Tablo 4).

Tablo 3. OAB değerlerinin gruplara göre karşılaştırılması

\begin{tabular}{|c|c|c|c|c|}
\hline & EPIDURAL & SPINAL & \multirow[t]{2}{*}{$\mathbf{T}$} & \multirow[t]{2}{*}{$\mathbf{P}$} \\
\hline & Ort \pm ss & Ort \pm ss & & \\
\hline OAB preop & $107,07 \pm 13,93$ & $114,43 \pm 15,33$ & 1,948 & 0,056 \\
\hline OAB 0 & $102,13 \pm 14,06$ & $113,20 \pm 17,04$ & 2,744 & 0,008 \\
\hline OAB 3 & $97,23 \pm 12,59$ & $100,73 \pm 15,07$ & 0,976 & 0,333 \\
\hline OAB 6 & $96,70 \pm 14,65$ & $95,53 \pm 17,17$ & $-0,283$ & 0,778 \\
\hline OAB 9 & $95,57 \pm 16,04$ & $94,63 \pm 14,57$ & $-0,236$ & 0,814 \\
\hline OAB 12 & $96,40 \pm 15,56$ & $93,00 \pm 15,63$ & $-0,844$ & 0,402 \\
\hline OAB 15 & $97,43 \pm 15,64$ & $91,97 \pm 16,72$ & $-1,308$ & 0,196 \\
\hline OAB 20 & $94,97 \pm 15,96$ & $89,77 \pm 17,66$ & $-1,197$ & 0,236 \\
\hline OAB 25 & $92,87 \pm 15,02$ & $89,60 \pm 17,81$ & $-0,768$ & 0,446 \\
\hline OAB 30 & $92,87 \pm 12,94$ & $91,23 \pm 16,45$ & $-0,427$ & 0,671 \\
\hline OAB 35 & $93,07 \pm 16,84$ & $87,00 \pm 16,84$ & $-1,395$ & 0,168 \\
\hline OAB 40 & $91,93 \pm 12,60$ & $88,43 \pm 14,06$ & $-1,015$ & 0,314 \\
\hline \multirow[t]{4}{*}{ OAB 45} & $90,83 \pm 14,72$ & $89,93 \pm 15,46$ & $-0,231$ & 0,818 \\
\hline & $F=1846,61$ & $F=1576,87$ & & \\
\hline & $\mathbf{P}<0,001$ & $\mathrm{P}<0,001$ & & \\
\hline & \multicolumn{2}{|c|}{$F=0,051, \quad P=0,823$} & & \\
\hline
\end{tabular}

Gruplar arasında periyodik ölçümlerde QTac yönünden istatistiksel olarak anlamlı bir fark bulunmadı ( $>0,05)$. Grup içi değerlendirmede her iki grupta preoperatif QTac değerlerine göre diğer periyotlarda ölçülen QTac değerlerinin düştüğü görüldü $(\mathrm{p}<0,001)$. Gruplar arası değerlendirmede, epidural grubundaki QTac değişimi ile spinal grubundaki QTac değişimi arasında istatistiksel olarak anlamlı fark yoktu ( $>00,05)$ (Tablo 5).

Tablo 4. QTa değerlerinin gruplara göre karşılaştırılması

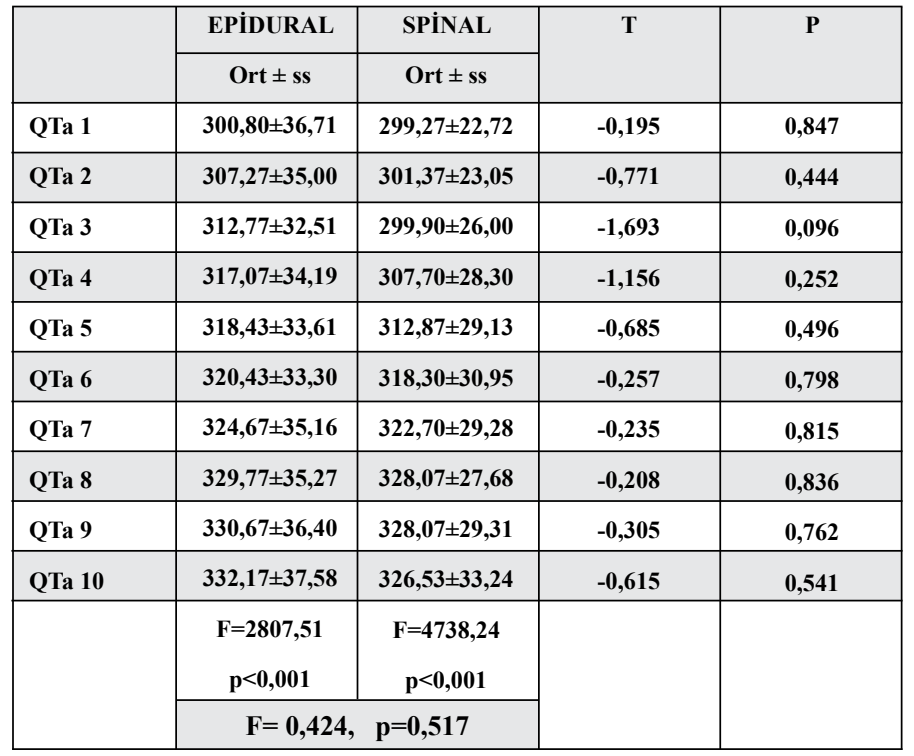

Gruplar arasında periyodik ölçümlerde 4. ve 5. periyotlardaki QTacd yönünden istatistiksel olarak anlamlı fark bulundu $(p<0,05)$. Grup içi değerlendirmede spinal anestezi grubunda 8 . ve 9. periyoddaki OTacd değerleri diğer tüm ölçümlere göre önemli düzeyde yüksek olarak bulundu $(\mathrm{p}<0.001)$. Epidural anestezi grubunda ise 8 . periyoddaki QTacd 1. 3. ve 7. ölçümlere göre, 2. ve 5. periyoddaki QTacd ise 1. ve 3. ölçümlere göre daha yüksekti $(p<0,001)$. Gruplar arası değerlendirmede, epidural anestezi grubundaki QTacd değişimi ile spinal anestezi grubundaki QTacd değişimi arasında istatistiksel olarak anlamlı fark bulunmadı $(\mathrm{p}>0,05)$ (Tablo 6).

Tablo 5. QTac değerlerinin gruplara göre karşılaştırılması

\begin{tabular}{|c|c|c|c|c|}
\hline & EPIDURAL & SPINAL & \multirow[t]{2}{*}{$\mathbf{T}$} & \multirow[t]{2}{*}{$\mathbf{P}$} \\
\hline & Ort \pm ss & Ort \pm ss & & \\
\hline QTa 1 & $346,77 \pm 26,86$ & $352,03 \pm 26,02$ & 0,771 & 0,444 \\
\hline QTa 2 & $353,80 \pm 20,81$ & $353,07 \pm 25,03$ & $-0,123$ & 0,902 \\
\hline QTa 3 & $358,20 \pm 19,96$ & $357,07 \pm 27,55$ & $-0,182$ & $\mathbf{0 , 8 5 6}$ \\
\hline QTa 4 & $361,93 \pm 23,12$ & $360,13 \pm 26,93$ & $-0,278$ & 0,782 \\
\hline QTa 5 & $362,10 \pm 24,49$ & $359,87 \pm 25,88$ & $-0,343$ & $\mathbf{0 , 7 3 3}$ \\
\hline QTa 6 & $358,90 \pm 20,24$ & $360,33 \pm 27,15$ & $\mathbf{0 , 2 3 2}$ & 0,817 \\
\hline QTa 7 & $365,63 \pm 29,36$ & $359,67 \pm 26,77$ & $-0,823$ & $\mathbf{0 , 4 1 4}$ \\
\hline QTa 8 & $366,63 \pm 29,44$ & $361,63 \pm 27,57$ & $-0,679$ & $\mathbf{0 , 5 0 0}$ \\
\hline QTa 9 & $365,97 \pm 28,93$ & $356,73 \pm 32,29$ & $-1,166$ & 0,248 \\
\hline \multirow[t]{4}{*}{ QTa 10} & $366,03 \pm 29,36$ & $358,77 \pm 29,06$ & $-0,963$ & 0,339 \\
\hline & $F=7658,29$ & $F=5931,49$ & & \\
\hline & $\mathbf{P}<\mathbf{0 , 0 0 1}$ & $\mathbf{P}<0,001$ & & \\
\hline & \multicolumn{2}{|c|}{$F=0,184, \quad P=0,669$} & & \\
\hline
\end{tabular}

\section{Tartışma}

Bölgesel anestezinin genel anesteziye oranla vital bulgular ve operasyon sırasında oluşan endokrin ve metabolik yanitlar üzerine olan olumsuz etkilerinin daha az olduğu bilinmektedir. Kan kaybı, tromboemboli, kardiyak ve solunumsal komplikasyonların daha az olması, postoperatif gastrointestinal fonksiyonların hızla düzelmesi ve üstün bir postoperatif analjezi sağlaması da bölgesel anestezinin ilgi

Tablo 6. QTacd değerlerinin gruplara göre karşılaştırılması

\begin{tabular}{|c|c|c|c|c|}
\hline & EPIDURAL & SPINAL & \multirow[t]{2}{*}{$\mathbf{T}$} & \multirow[t]{2}{*}{$\mathbf{P}$} \\
\hline & Ort \pm ss & Ort \pm ss & & \\
\hline QTa 1 & $22,80 \pm 6,08$ & $24,17 \pm 9,70$ & 0,654 & 0,516 \\
\hline QTa 2 & $28,37 \pm 12,37$ & $26,23 \pm 16,10$ & $-0,576$ & 0,567 \\
\hline QTa 3 & $23,50 \pm 8,41$ & $22,33 \pm 8,89$ & $-0,522$ & 0,604 \\
\hline QTa 4 & $26,70 \pm 10,18$ & $21,47 \pm 8,36$ & $-2,176$ & 0,034 \\
\hline QTa 5 & $29,20 \pm 12,33$ & $22,83 \pm 8,74$ & $-2,308$ & 0,025 \\
\hline QTa 6 & $25,90 \pm 11,76$ & $21,87 \pm 9,47$ & $-1,463$ & 0,149 \\
\hline QTa 7 & $24,27 \pm 13,14$ & $22,50 \pm 13,21$ & $-0,519$ & 0,605 \\
\hline QTa 8 & $31,03 \pm 16,89$ & $32,17 \pm 14,97$ & 0,275 & 0,784 \\
\hline QTa 9 & $27,03 \pm 11,00$ & $34,73 \pm 22,62$ & 1,677 & 0,101 \\
\hline \multirow[t]{4}{*}{ QTa 10} & $26,27 \pm 10,91$ & $28,67 \pm 14,54$ & $\mathbf{0 , 7 2 3}$ & 0,472 \\
\hline & $F=534,32$ & $F=538,64$ & & \\
\hline & $\mathbf{P}<\mathbf{0 , 0 0 1}$ & $\mathbf{P}<\mathbf{0 , 0 0 1}$ & & \\
\hline & \multicolumn{2}{|c|}{$F=0,258, \quad P=0,613$} & & \\
\hline
\end{tabular}


görmesine neden olmaktadır (Collins, 1993; Erdinç ve ark., 2005). Rejyonel anestezi tekniğinde kullanılan ideal anestezik ajanda istenen özellikler; ameliyat süresince etkili anestezi ve analjezi sağlaması, hızlı etki başlangıcı, allerjik reaksiyona neden olmaması, toksik doz sınırının yüksek olması ameliyat sonrası dönemde analjezik etkinin devam etmesi ve en önemlisi de santral sinir sistemi ve kardiyovasküler sistem yan etkilerinin minimal olmasıdır (Kayaalp, 1990). Amino-amid yapıda bir lokal anestezik olan bupivakain lokal infiltrasyon, periferik sinir blokları, epidural ve spinal anestezide sık olarak kullanılmaktadır. Rejyonel anestezi uygulamalarında güvenle kullanılan bupivakainin yanlış intravasküler enjeksiyonu sonrası ölümcül kardiotoksik etkiler görülebilmektedir. Kardiovasküler yan etkilerinin önemli nedeni bupivakainin sodyum kanallarından yavaş ayrılmasıdır (Reiz ve Nath, 1986; Huang ve ark., 1998). Çalışmamızda hastalara önerilen doz aralığına uygun olarak epidural anestezide $20 \mathrm{ml}(100 \mathrm{mg}) \% 0,5$ 'lik izobarik bupivakain, spinal anestezide $3 \mathrm{ml}(15 \mathrm{mg}) \% 0,5^{\prime}$ lik izobarik bupivakain uygulandi.

Hastalarda her iki grubun demografik verileri arasında fark görülmedi. Çalışmamıza dahil edilen ASA I-II grubunda 22-68 yaşları arasında hastalardır. Ek bir patoloji olmadan sadece yaş kendi başına aritmi insidansını arttırmadığ için, yaşlar arasındaki bu fark klinik olarak önemli sayılmadı (Miller, 2000).

Rejyonel anestezi uygulanan hastalarda seviyeye bağlı olarak bloke edilen sempatik liflerin sayısı ile orantılı hipotansiyon gelișebilir. Seviyenin yükselmesi ve torakal üst seviyelere yayllim tam sempatik denervasyona neden olabilir. Sempatik denervasyon bölgesinde arter ve arterioller dilate olmakta, total periferik direnç ve kan basıncı düşmektedir (Kayhan, 2004). Literatürde yüksek seviyeli nöroaksiyel blokaja bağlı kardiyopulmoner arrest vakaları bildirilmiş olup, genellikle etyolojik faktör T1-T4 seviyesinde sempatik blokaj nedeniyle karşıllksız kalan vagal tonus veya hipotansiyona bağlı solunum merkezinin inhibisyonudur (Kayaalp, 2000). Çalışmamızda hiçbir olguda ciddi bradikardi, hipotansiyon ya da kardiyopulmoner arrest gelişmemiştir. Gratadour ve ark.'nın spinal anestezi uygulanan hastalarda yaptıkları çalışmada duyusal blok seviyesi yükselmemesine rağmen bazı olgularda hipotansiyon ve bradikardi gözlendiği ve bu hemodinamik değişimlerin parasempatik aktivitenin artışı ile gelişmiş olabileceğini belirtilmektedir (Gratadour ve ark., 1997). Carpanter ve ark. spinal anestezi uyguladikları 952 hastada da bradikardi insidansını \%13 bulmuşlardır. Bunun nedenini kalbe dönen venöz kan akımının azalmasına ve sempatik kardioakseleratör liflerin blokajına bağlamışlardır (Carpanter ve ark., 1992). Pither ve ark.'nın epidural anestezinin hemodinamik parametrelere olan etkilerini inceledikleri bir çalışmada 20. dakikadan itibaren OAB'nda başlangıç değerine göre $\% 6$ oranında düşme saptanırken kalp tepe atımında anlamlı farklılık bulunamamıştır (Pither ve ark., 2003). Cox ve ark.'nın histerektomi uygulanan 88 hastada faklı iki lokal anestezik ilaçla yapılan epidural anestezinin etkilerini araştırdıkları bir çalışmada; cerrahi boyunca rapor edilen en s1k yan etkinin hipotansiyon olduğu, kardiyovasküler değişiklikler açısından gruplar arasında belirgin farklılık görülmediği, hiçbir ciddi aritmi oluşmadığı bildirilmiștir (Cox ve ark., 1998). Ceșitli rejyonel anestezi uygulamalarında görülen hemodinamik değișikliklerle karșılaștırıldığında benzer olarak, bu çalışmada bizim çalıșmamızda da her iki grup içinde rejyonel anestezi uygulamasından sonra incelenen kalp hızı, OAB, $\mathrm{SpO} 2$ gibi hemodinamik parametrelerde düşüş görülmüşse de hastanın vital fonksiyonlarını önemli oranda etkileyecek derecede olmamıştır. Ayrıca hastalara önerilen dozlarda aynı lokal anestezik ilaç uygulanarak iki rejyonel anestezi yöntemi karşılaştırılmış ve bunun sonucunda da kalp hızı, OAB, SpO2 gibi hemodinamik parametrelerde spinal ve epidural anestezi arasında fark görülmemiştir.

Gerek genel anestezi uygulamalarında kullanılan intravenöz ilaçların ve inhalasyon ajanlarının gerekse rejyonel anestezi uygulamalarında kullanılan lokal anestezik ilaçların QT intervali üzerine olan etkileri daha önce de araştırılmıştır (Owczuk ve ark., 2005; Whyte ve ark., 2005 Aypar ve ark., 2007). Ancak spinal ve epidural anestezinin QT dispersiyonuna etkisini karşılaştıran bir çalışma yapılmamıştır. QT ile ilgili olarak son yıllarda QT interval süresinin bütününün artmasından daha çok, QTa intervalindeki uzamanın, artmış prekordial dispersiyonu yansıttığı ileri sürülmüştür (Malik ve Batcharov, 2000; Braunwald ve Zippes, 2001). Badiale ve ark. yaptığ 1 bir çalışmada kalp siklusundaki uzamaya bağlı olarak QTa'daki değişiklerin QTe(QT end)'ye göre daha önemli olduğu vurgulanmıştır (Stramba-Badiale ve ark., 1997). Benzer olarak, diğer bir çalışmada özellikle kalp hızı anormalliklerinin bulunduğu durumlarda QTa intervalinin ölçümünün QTe intervalinin ölçümünden daha önemli olduğu vurgulanmıştır (Dawey, 1999). QT intervali değerlendirilirken QTa dispersiyonunun daha önemli olduğunun ifade edilmesine rağmen yapılan çalışmaların çoğunda QTe dispersiyon değerleri kullanılmıştır.

Anestezi yönteminin QT mesafesine etkisini araşt1ran bir çalışmada alt abdominal cerrahi planlanan 50 hastada sevoflurane ile yapılan VIMA (volatil indüksiyon ve idame anestezisi) ve bupivakain ile yapılan spinal anestezini karş1laştırılmış ve QTd ve QTcd değerleri arasında gruplar arasında değişim yüzdeleri açısından fark bulunmadığı ifade edilmiştir (Akçay ve ark., 2004). Fakat son ölçüme bakıldığında QTcd değerlerinin başlangıç periyoduna göre değişiminde spinal grubunda \%13,49 oranında VIMA grubunda ise $\% 80$ oranında artış bulunmuş ancak bu fark anlamlı olarak değerlendirilmemişdir. Owczuk ve ark. kardiak sorunu olmayan hastalarda uygulanan spinal anesteziden sonra QT aralığ1$\mathrm{n}$ 1 incelemişler ve QTc'nin belirgin olarak uzadığını, ancak ciddi aritmilerin görülmediğini saptanmışlardır (Owczuk ve ark., 2005). Bizim çalışmamızda QTa ve QTac değişimi aç1sından spinal ve epidural gruplarda grup içi başlangıç ve son değerleri arasında anlamlı artış bulunmamasına karşın gruplar arasinda anlamlı bir fark saptanmadı. Epidural ve spinal grupların kendi içinde QTacd'nin tüm ölçümlerinde anlamlı fark görülürken, iki grup arasında iki ölçüm zamanı dışında fark saptanmadi. Tüm bu bulgular 1şığında aritmi patogenezinde önemli rol oynayan QT uzamas1 epidural ve spinal anestezi uygulanan hastalarda gerçekleşmekte ancak her iki anestezi yönteminde fark olmadığı görülmektedir. 
Sonuç olarak; Anestezi uygulamasından önce gelișebilecek hemodinamik değișiklere karșı alınacak önlemler sayesinde epidural ile spinal anestezi yöntemlerinin güvenle uygulanabileceği, hemodinamik parametreler ve QT uzama- sına neden olabilecek kardiyotoksik etkiler açısından önerilen dozlarda bupivakain kullanılarak yapılan epidural veya spinal anestezi yönteminin birbirine üstünlüğü olmadığı kanisina varildi.

\section{KAYNAKLAR}

Akçay M., Albayrak D., Akçay K.F., 2004. Sevofluran ile yapılan VIMA ve bupivakain ile yapılan spinal anestezi yöntemlerinin QT dispersiyonuna olan etkilerinin karşılaştırılması. Türkiye Klinikleri J. Anest. Reanimasyon. 2, 137-143.

Aypar E., Karagöz A.H., Ozer S., 2007. The effects of sevoflurane and desflurane anesthesia on QTc interval and cardiac rhythm in children: Pediatric Anesthesia. 17, 563-567.

Bardlesy H., Gristwood R., Baker H.,1994. Reduced cardiotoxicity of levobupivacaine compared with racemic bupivacaine: new clinical evidence Expert Opin. Invest. Drugs. 3, 1209-1212.

Braunwald E., Zippes D.P., 2001. Heart Disease. A Textbook of Cardiovascular Medicine. 6.th ed, Philadelphia: Saunders, 22112222.

Carpenter R.L., Caplan R.A., Brown D.L., Stephenson C., Wu R., 1992. Incidence and risk factors for side effects of spinal anesthesia: Anesthesiology. 76, 906-916.

Collins J.V., 1993. Principles of Anaesthesiology. Third Edition, Lea and Febiger. Philadelphia. 1445-1497.

Cox C.R., Faccenda K.A., Gilhooly C., Bannister J, Scott N.B, Morrison L.M.,1998. Extradural S (-)-bupivacaine: comparison with racemic RS-bupivacaine. Br. J. Anaesth. 80, 289-293.

Chester C., Bleckner L.L., 2005. Anaesthetic agents for advanced regional anaesthesia. Drug. 65 ,745-759.

Davey P.P., 1999. QT interval measurement: Q to Tapex or Q to Tend? J. Inter. Med. 246, 145-149.

Erdine S., Özyalçın S.N., Raj P.P., Heavner J., Aldemir T., 2005. Rejyonel Anestezi. Nobel Tıp kitapevleri Ltd, İstanbul. 185-191.

Erdine S., Özyalçın S.N., Raj P.P., Heavner J., Aldemir T., Yücel A., 2005.: Rejyonal Anestezi. Nobel Tıp Kitabevleri, İstanbul. $1-5$

Gratadour P., Viale J.P., Parlow J., Sagnard P., Counioux H., Bagou G., Annat G, Hughson R., Quintin L., 1997. Sympathovagal effects of spinal anesthesia assessed by the spontaneous cardiac baroreflex. Anesthesiology. 87,1359-1367.

Huang Y.F., Pryor M.E., Mather L.E., Veering B.T., 1998. Cardiovascular and central nervous system effects of intravenous levobupivacaine and bupivacaine in sheep. Anesth. Analg. 86, 797-804.

Irestedt L., Emanuelsson B.M., Ekblom A., Olofsson C., Reventlid H., 1997. Bupivacaine 7,5 mg/ml for elective caesarean section. A clinical and pharmacokinetic comparison of $150 \mathrm{mg}$ and $187.5 \mathrm{mg}$. Acta Anaesthesiol. Scand. 41,1149-1156.

Kayaalp O.S., 1990. Tibbi Farmokoloji. 5. Bask1, Feryal Matbac1lı, Ankara. 1682-1691.

Kayaalp S.O.,2000. Editör. Lokal anestezikler. Tıbbi Farmakoloji. 9. Baskı. Hacettepe Taş Ankara. 789-820.

Kayhan Z., 2004. Klinik Anestezi 2.Baskı. Logos Yayıncılık, İstanbul. 552-587.

Kayhan Z., 2004. Klinik Anestezi. 2. Bask1. Logos Yayıncılık, İstanbul. 503-523.

Malik M., Batchvarov V.N., 2000. Measurement, interpretation and clinical potential of QT dispersion: J. Am. Coll. Cardiol. 36, 1749-1766.

Miller R.D., 2000. Spinal, epidural and caudal anesthesia. Anesthesia; fifty edition. 491-1519.

Owczuk R., Wujtewicz M.A., Sawicka W., 2005. The influence of desflurane on QTc interval. Anesth. Analg. 101, 419-422.

Owczuk R., Sawicka W., Wujtewicz M.A., 2005. Influence of spinal anesthesia on corrected QT interval. Regional Anesth. Pain Med. 30, 548-552.

Pither C.E., Emanuelsson B.M., Reventlid H., Whitehead E., 2003. A comparison of the dynamics and pharmacokineticks of ropivacaine $7.5 \mathrm{mg} / \mathrm{ml}$ with and without epinephrine used for epidural anaesthesia in urological surgery. Clin. Drug Invest. 29, 245-253.

Reiz S., Nath S., 1986. Cardiotoxicity of local anaesthetic agents. Br. J. Anaesth. 58, 736-746.

Stramba- Badiale M.S., Locati E.H., Martinelli A., 1997. Gender and the relationship between ventricular repolarization and cardiac cycle length during 24-h holter recordings: Eur. Heart J. 18, 1000-1006.

Whyte S.D.,Booker P.D., Buckley D.G., 2005. The effects of propofol and sevoflurane on the QT interval and transmural dispersion of repolarization in children. Anesth. Analg. 100, 71-77. 